\title{
6. Transforming the Public University: Market Citizenship and Higher Education Regulatory Projects
}

\author{
Kanishka Jayasuriya
}

\section{Introduction}

This chapter explores the shifts within mass higher education and its governance over the last three decades. Mass higher education has changed substantially in tandem with the broader changes associated with the social and political compromises over that time. The crisis and transformation of the public university needs to be understood in this context. To this end, this chapter analyses the transformation of the public university as it relates to broader state and governance projects focusing on the crucial shift from the 1980s onwards with the emergence of new notions of market citizenship, bringing with it what has been referred to as 'structured opportunity markets' in higher education. These notions of market citizenship are given shape through an emerging higher education regulatory state, now governed by a range of formal and informal instruments including measures to enhance inclusion and participation within the market. It is these regulatory projects that develop and give legitimacy to the higher education market. Consequently, the development of the regulatory state and market-making has been deeply intertwined. In conclusion, I argue that the 'public' university does not disappear as such, but is reconstituted within these new regulatory arrangements and projects. This argument is illustrated with reference to recent initiatives in the Australian higher education sectors, such as the Bradley Report and the establishment of the Tertiary Education Quality and Standards Agency (TEQSA). 
Simon Marginson in his observations on the theme of the workshop that gave rise to this collection suggests - if I read him correctly - that much of the contention on the hollowing out or otherwise of the public university in the Anglo-Saxon world risks going in circles. He proposes that a more productive way would be to explore these debates in the context of higher education changes in East Asia and Russia. In a similar way, Collini (2011) too argues that it is not at all clear that this Anglo-Saxon model of the public research university to which we subscribe - namely, the provision of public benefit, open communication, the nurturing of a scholarly community, the creation of the new knowledge and open public communication - will be adopted by the fast-growing universities of China.

But then, what do we make of the notion of a public university? In agreeing with the broad tenor of the critique of the 'historical idea' of the public university, I propose to go beyond some of the sterile debates surrounding the notion of a 'public university'. So how do we define 'public' in the context of the 'public university'? At a minimum, we need to see that the 'public university' is not some 'Weberian' ideal type against which we can benchmark the role of the university. This is clearly evident in the tenor of much of the recent discussion of the public university which, particularly in Australia, Great Britain, and the United States, has been framed in the light of Cardinal Newman's classical ideal of the 'idea of the university'. This much-cited approach to higher education finds expression in the early work of those such as Newman and Humboldt. Newman (1976), for example, argued that the university was central to cultivating the public mind and 'national culture', and training the political elite.

Newman's essay has become a standard reference for those wishing to discuss the nature and purpose of university education. Similarly, Humboldt, writing in the different political economic context of industrial Germany, espoused a notion of the public university that combined industrial and civic elements. These familiar conceptualisations of the university, associated with Newman, Humboldt, and others are products of specific political and economic circumstances. For instance, the case of Humboldt and the consequent German emphasis placed on the state-regulated notion of university and professional autonomy could only be understood in the context of the late industrialisation projects of the Prussian/German state and its promotion of science and technology (Habermas 1987). To the extent that these notions constructed a 'public', it was defined in terms of inculcating 'national culture' and educating a professional and political elite.

It is not possible to read off the 'idea of the university' from its internal history (though this is important). For a more comprehensive picture, we need to see how this sense of the 'public' or the 'publicness' of the university itself has been constituted and shaped by political projects and the broader settlements 
that underpin them. In other words, politics and contending definitions of the 'public' have always been central to the process of constructing the public university and we need to keep away from reifying an ideal model of the public university that emerged in the 1950s. A good example of this 'ideal type' approach to the public university is found in Collini's much circulated article in the London Review of Books. In essence he argues that there has been a major shift from the world of Robbins to the managerial dictates of McKinsey as seen in the recent UK White Paper (Department of Business and Innovation 2011). As such, the principles of the White Paper are only 'the latest instalment in the campaign to replace the assumptions of Robbins's world with those of McKinsey's' (Collini $2011,14)$. This is a good point, but Robbins's world was itself a product of a certain kind of social democratic grammar of politics and what this leaves out - in the British context - is precisely the pressures of mass higher education in the 1960s, the role of the polytechnics in this process, and the way these shifts reflect more profound changes in a broader shift from the postwar social democracy, which I refer to below as 'new forms of market citizenship'. In other words, what is missing in this argument is that the state itself has been retooled over the course of the last 30 years in a range of policy areas. The governance of higher education is no exception.

\section{The changing mission of the public university, state projects, and citizenship}

The institutional and ideological context of the public university is constantly being redefined, and to view these changes through the prism of an ideal point of view is to misunderstand the way the notion of the 'public' itself has changed. The broader argument here is that neoliberalism - the project of market reform that has shaped Australian politics and public policy - was not so much a retreat of the state but a restructuring and transformation of the state. The state has remained pivotal to this process of neoliberalisation by creating new forms of market-like disciplines and techniques that were often layered onto other more social-democratic oriented policies and tools. The regulatory state has been the pivotal instrument of this transformation and, in turn, changes in policies, instruments, and tools that govern higher education exemplify a transformation of the state. The higher education regulatory state imposes 'disciplines' through market-like signals, incentives, and accountability benchmarks on institutions designed to increase allocative efficiency and pursue a variety of social objectives. These objectives were often in tension but they were linked together through varied political projects - social-democratic neoliberal or 'allocative efficiency' - of market citizenship. Hence, state restructuring and the diverse forms it has 
taken is crucial to the understanding of policy changes to higher education including the proposed initiatives introduced by the Abbott government and the Minister for Education, Christopher Pyne (McPhee 2014).

In order to understand the nature of the contemporary transformation of the public university, we need to contrast it with the development the post-Second World War public university and its associated political project of national modernisation. In the postwar period there has been a broad convergence of the institutions and practices of the public research university across the globe. Of course, this is a broad brush statement. The importance of these functions varied across time and place, and was layered on to earlier traditions and institutions. Some of these key functions included national projects of modernisation - the case of the Research Schools at The Australian National University (ANU) in Australia; an emphasis on the importance of the public university as a vehicle of social democratising to promote social mobility; and, a strong research and training mission - particularly evident in the early postwar years in the US public universities - with strong publicly mandated research missions in the basic sciences often linked to, or funded through, the military industrial complex.

In a nutshell, it shaped a notion of publicness which in the case of the Californian Master Plan - driven by its public university system - embodied some of the components of this social citizenship model of the public university. In this context, as Brady and Konczal (2012) note, the Master Plan contained a commitment to educate Californian students with minimal fees and was intended to facilitate the social mobility that was seen as central to the New Deal social settlement that had shaped some of the assumptions about the role of the Californian public university system. This was not simply about the public university but a broader state project of 'citizenship building' (Brady and Konczal 2012; Douglass 2000). The higher education sector in the postwar period emerged out of the domestic politics of broader social settlements that legitimated the idea of higher education as a public good, and the geopolitics of the Cold War which, particularly in the United States, sustained an era of big science.

For this reason, the public university - particularly the notion of the 'public' - needs to be seen in relational terms as it expanded in the postwar period and became the subject of continuing debate and contestation over participation in, and equality of access to, the benefits of higher education. Yet, the point is that various models of the public university not only served to enhance a particular conception of the public good, but also embodied in its institutional practices a nationally framed social citizenship (Robertson 2007). 
The question we need to ask is: Why is the public research university seen to be either in crisis or in transformation across the globe? One response to this question is that it is a product of the structural pressures across the advanced industrial states, and includes: (a) a rapid expansion of the university system ('massification'); (b) growing constraints on funding, teaching, and research; and, (c) the growing salience of selection and ranking, especially in research. In turn - and crucially - these pressures on the public universities are themselves located in the 'various crises' of the postwar social settlement across advanced industrial states. In addition, the shift towards a post-industrial service-based economy has transformed the kind of training required for the post-industrial economy. In sum, this move away from the public university as a common source of social citizenship, as Fischman, Igo and Rhoten $(2007,123)$ astutely argue, is mirrored in a shift in the relative weight of public and private benefit in higher education towards the private benefit. This is a shift which continues to have constrained the impact on what we have called the 'social democratising' effects of the public university. Locating the transformation of higher education in these terms allows us to view the public university - indeed the very term 'public' - in the context of its relationship to broader political projects of citizenship.

From this perspective, the 'public university' and its transformation should be analysed from the viewpoint of the sustainability of state and political projects to transform public universities - as, for example, in the Californian Master Plan - in response to wider social and economic transformations. This resonates with Craig Calhoun's argument $(2011,15)$ that there is a 'direct connection between the larger societal crises and that in higher education. Universities were central to projects of both the "welfare state" and the developmental state during the decades after World War 11.' During the crisis of the 1970s and 1980s, public universities were the focus for discontent with these programs when they failed to live up to expectations particularly with regard to democratisation, and became the subject of critique from the left and the right (Calhoun 2011, 15). The fate of the Californian Master Plan is a good exemplar of these changes assailed by Ronald Reagan when he was California's Governor, and with the Vietnam War making the university system the site of political struggle between the left and right (Brady and Konczal 2012). It is useful to recall how changes in geopolitical context were central to the emergence and the crisis of the public university and the broader political consensus that sustained the project of the public university in the postwar era.

While the postwar development of the university was dependent on notions of social citizenship, equally pivotal - and this is something that is beyond the scope of this chapter - are the broader geopolitical projects that animated the expansion of the public university system across the world. In the US, the Cold 
War geopolitics fed the appetite of 'big science' in major research universities. In fact, the New Deal inspired both the project of democratisation of higher education and the Cold War geopolitical program that spurred the creation of 'big science' research initiatives and formed the cornerstone of the expansion of the public university system in the postwar period. Here, the Californian university system was also at the centre of a key defence-related research enterprise. In Australia, the relationship between 'big science' and 'geopolitics' was never as significant as in the US, but the Colombo Plan (which is now much touted by the Coalition) was a creature of Cold-War politics which sought to encourage members of the Asian elite to inculcate 'Western' values. The broader point is that a trio of forces - (a) the 'massification of the university system; (b) the project of social citizenship, and, (c) the geopolitics of the Cold War that sustained substantive research investment - went hand in hand.

These shifts in higher education played a role - albeit in a different key - in Australia. In her Menzies Oration, Janice Reid (2012) points to how a broad notion of social citizenship was central to the expansion of the postwar university system in Australia. As she points out (Reid 2012, 9), despite their differences, and particularly Whitlam's willingness to use expenditure on universities to promote social equality, both Menzies and Whitlam 'saw universities as central in driving economic advancement and social transformation. Those threads spun out through the generations and though rediscovered and reworked in policy funding reforms every decade or so, can still be traced back to these figures.' Reid's point is well taken but we should not diminish the political distance between Whitlam and Menzies in respect to higher education as it is clear that the Whitlam reforms were designed to promote the social democratisation of higher education, whereas Menzies saw it as an instrument to promote stability and integration among the middle class. Whitlam, of course, made this central to his political project of social democratic modernisation after his victory in 1972. In fact, it is interesting that the changes to the public university have featured prominently in Australian Labor's - each very different - modernising projects from Chifley through Whitlam and Hawke-Keating to the RuddGillard governments. Despite these differences, both Whitlam's and Menzies' approaches to higher education - to use Collini's terminology - were in the world of Robbins located in - albeit different - projects of social citizenship underpinned by the social settlement between capital and labour that marked the postwar period.

Moreover, Reid points out how the peer-driven governance as exemplified by the Universities Commission complemented these notions of social citizenship. As she implies, the bureaucratic governance of the university - which in the postwar period was a lot stronger in Australia than in other English-speaking countries - was often in concert with what Moran (2003) has described as 
'club government'. In turn, this 'club government' depended on the use of professional autonomy and the use of 'voice' in shaping the internal governance of the university. Hence the point to be emphasised - and missing in various critiques of contemporary corporate culture of universities - is how these internal processes were connected to wider state projects of higher education.

In several countries, the 'long 1970s' were crucial to the crisis of the various models of the public university. In my view the ongoing crisis and transformation of the public university has to be located in the context of the broader social and economic crisis of the long 1970s. In Australia, the 1970s were crucial to the future evolution of the public university. The Whitlam government abolished fees and sought to increase the capacity of the university system (Marginson 1997c). And in line with Calhoun's thinking, the public university was itself a crucial component of Whitlam's modernising and, we might add, 'nationalising' project. The great irony of the Whitlam reforms is that the model of the public research university that his government consolidated relatively late in Australia was to be so short-lived as the broader ideas and practices of social citizenship and its underlying social democratic grammar of politics came under sustained pressure. These pressures stemmed from both the changing social and economic circumstances with the end of the long postwar economic growth, and the emergence of fiscal crisis of the state (O'Connor 1979). In addition, this was a period of sustained attack on these notions of social citizenship from conservative political movements.

If we adopt this relational framework, we have the advantage of moving away from what is an uncritical analysis of the pre-Dawkins era made by critics, of the recent emphasis on marketisation (Dawkins 1988). This is reflected in the tendency to look somewhat nostalgically at a so-called pre Dawkins golden era. Of course, what this overlooks is the very tumultuous years during the 1970s, which included not just the introduction of free education and expansion of the system, but also the significant university cuts made by the LiberalNational Coalition in the 1970s (Marginson 1997c). It was in this context that John Dawkins introduced his university reforms. The Hawke-Keating reforms and modernisation project sought to achieve democratic objectives within this framework of market reform (Johnson 2000; Jayasuriya 2010a). In this vein, modernisation became a political project that sought to adapt social democracy or its particular Laborist variant to the convulsion of global capitalism that effectively undermined the postwar economic and political regimes and corresponding social foundations (Gamble 2006; Jayasuriya 2006). If we follow this argument, the Dawkins reforms need to be analysed in a broader context of the acceleration of programs of market reform in the economy and in the public sector - neoliberalism if you like - and continuation of the older social democratic objective of expanding mass education. 
This social democratic variant of neoliberalism sought to reconcile the 'massification' of the university with the imperatives of market reform. But central to this major project was an attempt to cast the 'public university' within the context of a new notion of market citizenship that sought to meet the dual objectives of expanding 'human capital' and the inclusive participation of citizens in a globally competitive economy. Higher education - as was to be the case with the Rudd-Gillard government - became pivotal to the way in which social democratic parties attempted to embed, and adapt to, the broader processes of neoliberalism or market reform. These changes served to transform the nature and function of the public university.

\section{Higher education regulatory state and the making of market citizenship}

The net impact of these changes - economic reform and the acceleration of university participation - is not so much the hollowing out of the 'public', but rather, the conception of the university framed in terms of market citizenship. In turn, these notions of market citizenship find expression in broader regulatory projects that underpin the reform of the public university. Market citizenship is defined here as promoting the inclusion and participation of citizens within the market economy. As such, market citizenship is not aimed towards redistributing resources but towards enhancing participation within the market. These forms are best described as socialising neoliberal or market reform programs (Jayasuriya 2006; Cerny 2010). Here, the Dawkins reforms were central not just in the modernisation of the university but in the way in which they were seen as constituting an integral part of a notion of a market citizenship. Translating this into the university sector meant that the reforms were designed to enhance individual skills. This process was seen to be essential to participating in the new knowledge economy in a context where innovation was crucial for economic growth. Similarly, there was an emphasis on industry linkages with the university sector. It is important to note that these trends toward market citizenship are part and parcel of what one higher education scholar (Douglass 2009) refers to as 'structured opportunity' markets. According to Douglass $(2009,3)$, these markets are distinguished by a 'decidedly more differentiated, consumer and market-oriented approach to expanding access and managing enrolment, with various budget and structural limits, and with one goal of supporting greater socioeconomic mobility in society, and economic development'. There are various components of this model: greater global reach of the institutions, more differentiated institutional missions, diversified funding, and providers; and I would add, the growing role of privately managed online education platforms. 
A powerful example of this market citizenship was the Higher Education Contribution Scheme (HECS) that sought to reallocate and privatise some of the burden of financing the 'massification' of the university system in order to widen participation. Underlining the notion of market citizenship, the primary rationale for the scheme was not just to shift the burden to private individuals, but to recalibrate the relationship between the private and public contributions. More importantly, the introduction of student fees has provided a powerful regulatory tool to impose market discipline on the university sector. Regulation through fees enables the calibration of both market and social objectives via student contributions. The significance of these policy changes lies not so much on the level of fees but on the way these changes foster a regulatory instrument and form governance arrangements that made market disciplining a central objective of higher education policy. And these market-disciplining forms of governance - via a range of regulatory tools and instruments - have led to a partial reconstituting of the 'public' as consumers of public services.

There has been a differing emphasis by Liberal and Labor on these various components of market citizenship. It is not so much that the world of Robbins had been replaced, as in the UK by McKinsey - to use Collini's evocative phrase - but that the social democratic world in which Robbins operated has now been supplanted by a more neoliberal or market-oriented world where market disciplining through regulation has become much more pivotal, not just in the provision of public utilities or economic governance but also in sectors such as higher education. This has not hollowed out the public university, but has served to underline different notions of 'publicness', particularly with regard to their role in state projects.

Resonating with the earlier Dawkins reforms, there is a social democratic notion of 'market citizenship' that comes to the fore in the Bradley Report commissioned by the Rudd government soon after taking office. The strategic rationale of the Report and the market-citizenship approach is most evident in its approving nod to the OECD statement on higher education. In fact, the OECD has been an important influence in shaping the convergence of higher education policies across both developing and developed countries. The Bradley Report quotes the $\operatorname{OECD}(2008,23)$ to argue that:

the widespread recognition that tertiary education is a major driver of economic competitiveness in an increasingly knowledge-driven global economy has made high quality tertiary education more important than ever before. The imperative for countries is to raise higher-level employment skills, to sustain a globally competitive research base, and to improve knowledge dissemination to the benefit of society. 
But, in addition to this version of the public university as an instrument of human-capital building was the allied notion of inclusion and participation in higher education. Hence one of the key recommendations of the Bradley Report - exemplified by the embedded neoliberal version of market citizenship - was the clarion call for greater participation of disadvantaged groups in the higher education system.

This report (Bradley Report 2008, xiv) went on to argue: 'All institutions in receipt of Commonwealth funds for teaching will be expected to establish initiatives to increase both the enrolment of, and success of, students from disadvantaged backgrounds.' It called for innovative governance projects such as partnership with schools and other educational institutions to enhance participation. More importantly, the report envisaged setting targets for disadvantaged groups, and tying budgetary allocations to such targets in order to enhance their participation within the system (p. xii). At the same time, it advocated a demand-driven financing system (151-74). In all of these proposals, we find that the construction of a regulatory architecture is designed with a view to calibrating the balance between social objectives and market disciplines in order to produce citizens fit for the market.

One of the key means through which these notions of market citizenship were given shape in Australia and the UK was through a broad-ranging regulatory order that enabled both the monitoring of quality and the operation of the demand-led student system. This may be a case of 'Moscow on Molongo' as described by Corden (2005) - the curious combination of markets and regulation. But Corden's (2005) implication is that somehow regulation is an obstacle to the implementation of market citizenship in higher education. Instead, I would suggest that the two are deeply intertwined. Regulation is the means through which the higher education market is guided to enhance the often inconsistent - political projects of market citizenship. It is this emerging regulatory governance of higher education that is shaping the internal higher education market and the state.

King (2006), one of the very few writers to conceptualise higher education through a regulatory prism, notes that the close relationship between state and higher education is created by an increasingly rule-governed system of higher education. These rules establish broad directives that regulate the conduct of institutions. Consequently, King argues that it is possible to identify this as a 'higher education regulatory state' (King 2006, 8). The Bradley Report $(2008,97)$ recommended the creation of the national regulatory system 'on the basis that the regulatory framework for tertiary education is in need of a major overhaul and that the regulation of international education should be considered in a broader context which involves the creation of a national regulatory body'. 
The Australian Government has now established the tertiary education regulator - the Tertiary Education Quality and Standards Agency (TEQSA) that has become the central regulatory agency of higher education. One senior official has described this agency as having more procedural power than any other comparable agency in any high-quality university system (The Australian, 6 July 2011). It sets threshold standards for the higher education system and will shape the internal governance of institutions. It is beyond the scope of this chapter to analyse the role of the regulatory state in selecting and sorting research excellence such as the Excellence in Research for Australian (ERA) initiative in Australia, which is a crucial dimension of the emerging higher education regulatory state.

It is important to recognise that the regulatory state works not through direct intervention in higher education institutions - although this is possible - but indirectly through the setting of benchmarks and threshold standards. In this way, regulation is implanted in the heart of institutional structure which in a way mirrors other regulated industries such as finance. In tandem with these changes, universities are now at the crossroads of other overlapping regulatory regimes. For example, they are now key intermediaries in the immigration and visa system, adding a further layer of complexity to regulatory environment in which the modern public university operates. In the UK, an example is the recent experience of a London metropolitan university which lost its capacity to recruit international students after being non-compliant with the regulatory regime of the now defunct UK Border Authority (UKBA). The university has not only become subject to higher education regulatory regimes, but is also the site for a range of complex overlapping regulatory regimes.

Some have sought to describe the modern public university as an institution dominated by a corporate culture, but in my view this description neglects the wider and deeper processes of state transformation which are imprinted on higher education institutions. Hence a better description of these cultural changes is to depict these components of a developing 'regulatory culture' that is deeply entrenched within the university system. A manifestation of this regulatory culture within institutions is the emergence of new regulatory intermediaries, a notion that is used by King (2006) to describe regulatory intermediaries as inhabiting the regulatory space between regulator and regulated key groups which are positioned to play critical intermediary roles. These include the Quality Assurance Agency (QAA), part-time assessors or auditors drawn from the academic community (other "regulatory intermediaries" for external quality regulation are senior institutional leaders and quality managers in universities and colleges') (King 2006, 11). But these regulatory intermediaries are not merely the external auditors; they are also located within the university itself. The 'audit culture' is part and parcel of the regulatory state that creates and 
enhances these regulatory actors within the university. The rise of the higher education regulatory state enhances the role and power of these regulatory intermediaries within the university.

For this reason one of the most important implications of this emergent 'regulatory culture' is the increasing marginalisation of 'voice' - peer governance - within the university system. In this regard, TEQSA is as far as you can get from the old peer-driven University Commission, or as Moran (2003) puts it, in a British context 'club governance', towards the more formalised rule-driven system of governance. In turn this regulatory order - and I leave this issue for another day - has considerable impact on professional autonomy and control. Again, the growing regulation of professional activity within the university is complemented by a similar regulation of professions in the areas of law and health. It does suggest that the internal governance of the public university is not due to whims of managerialism, but deeply rooted in the emerging higher education regulatory state.

The thrust of this chapter is to suggest that exclusive focus on the operation markets is to risk losing sight of the rationale and principles around which the regulatory order is being established. Here, it seems to me that the particular social democratic variant of this market citizenship, which can be traced through to both the Dawkins and Bradley reforms, stems from how they sought to incorporate new notions of inclusion within this regulatory order. Yet, such measures eschew the issues of inequality that formed a significant element of the Whitlam project. But my point is this: from the issue of benchmarking participation of disadvantaged students to the differentiated institutional mission statements of institutions, the market-citizenship model of higher education forms part of a larger higher education regulatory project. Regulatory institutions become the mechanisms through which market reform is institutionally embedded, and this includes the kinds of inclusive participation sought by the Bradley Report.

From this regulatory perspective, it is not the market or state that is important, but the way in which the market is constituted through a variety of political and policy instruments. Once established, these new regulatory architectures develop their own institutional and political logic that provides the basis for further reform and experimentation. In this regard, there may well be-regardless of initial intent - a drift towards more intensive forms of market disciplining and expansion, especially so with the election of the Liberal-National Party Coalition government. The Coalition government has already signalled a shift away from inclusive notions of market citizenship towards an understanding of regulation as a project of allocative efficiency to discipline higher education, to build skills and capacities to enable business to operate in a competitive global economy. 
An equally important dimension of this regulatory state is the emphasis it places on issues of accountability and legitimacy. Accountability, I would argue, is not simply a technical issue; it is a distinctive political process that helps to give legitimacy to the notion of market citizenship. Audits and quality inspections such as the ERA are the bread and butter of the new higher education regulatory governance. The importance of these 'accountability' measures is emphasised by Adelman $(2008,6)$ who in relation to the Bologna Process notes that:

A qualifications framework is a statement of learning outcomes and competencies a student must demonstrate for a degree at a specific level to be awarded. It is not a statement of objectives or goals. It is not a wish list. It is a performance criterion. When an institution of higher education is governed by a qualifications framework, it must 'demonstrate' that its students have 'demonstrated'.

But this is inescapably a political process, and as Harrington and Turem (2006, 201) argue, allows us to see the relationship between accountability discourses and practices - such as, say, a qualifications framework - in the context of its relations and location within the broader patterns of social, political, and legal relations. They also note that framing accountability as a form of political governance has the distinct advantage of identifying and analysing developing forms of accountability and public regulation in terms of 'how it is understood, shaped and ultimately mobilized as a powerful political symbol to legitimate a certain type of regulatory regime' (ibid).

The choice of a particular accountability strategy reflects the strategic preference of key actors in three main ways: first, it rules out alternative ways of conceiving accountability; secondly, it helps to mobilise and favour certain kinds of policy outcomes against other outcomes; finally, it enables the inclusion or marginalisation of private and public actors. This does not preclude the conflict and contestation over the nature of 'accountability', but none of this challenges the parameters of the regulatory order. Here, accountability plays a crucial role in giving expression to the 'public' within this regulatory governance and thereby helps to shape new forms of 'publicness'. I would argue that in the higher education area, these notions of accountability, and the complex regulatory tools of monitoring and enforcement, have helped to promote and expand the notion of market citizenship through imposition of disciplines to benchmark efficiency and social objectives.

Given the recent emphasis on the issues of student mobility, particularly to Asia, we are likely to see an expansion of the higher education regulatory toolbox as a way of enabling Australian universities to compete more vigorously in the knowledge-based geo-economic order. Here, there is a discernible shift from the geopolitics of the Cold War towards a greater emphasis on geo-economic competition in knowledge and innovation. The Asian Century White Paper 
placed considerable emphasis on enhancing student mobility as a way of building Asia capability. This geo-economic project is echoed in the Coalition's emphasis on a reversed Colombo Plan to send Australian students to Asia in order to build the relevant Asian capabilities which can enable Australian companies to adjust to the new economic order in Asia. Again, this new Colombo Plan will depend on a rather complex series of rules that will feed into a broader accountability architecture.

\section{Conclusion}

The distinctive element of the 'publicness' that underpins market citizenship in higher education is now dissociated from the funding, control, and mission of the public university. Universities are not so much privatised or the 'public' hollowed out, but have increasingly become hybrid institutions consisting of a mixture of public and private funding and control. The 'public' character of the institutions is increasingly secured by notions such as 'public value' benchmarking located within the broader regulatory regimes. This dissociation between the 'public character' of the university and the regulatory regime creates an inbuilt bias towards a continuing shift in favour of increasingly privatised forms of funding. More substantively, it inhibits the collective or common space that is vital for the university to continue as a site of democratic engagement and free inquiry.

To conclude, the thrust of this chapter has been to understand the complex and intertwined links between the transformation of the public university and the rise of new patterns of regulatory governance. I argue that the notion of market citizenship is central to understanding these regulatory projects and how they seek to embed this market process in a particular version of human capital formation and social inclusion. This is, of course, one variant of the regulatory project and, under a Coalition government, we are likely to see some significant changes to the nature and forms of the higher education regulatory order. Whatever the changes, it looks like regulation is here to stay and will increasingly consist of juggling four elements: (a) the massification of higher education, (b) the hard budget constraints, (c) the pursuit of research excellence, and (d) the related importance of the university as a site of geoeconomic competition. This will prove to be a difficult quartet to juggle, and one is likely to see a period of constant regulatory change and innovation.

Yet, in all of these changes what seems to be absent is the notion of the university as a site of democratic engagement and contestation in an increasingly globalised world. Rather than going back to various 'ideal types', we need to develop new forms of 'publicness' for the university. 
This text is taken from Through a Glass Darkly: The Social Sciences Look at the Neoliberal University, edited by Margaret Thornton, first published 2014, this version 2015 by ANU Press, The Australian National University, Canberra, Australia. 